\title{
A Study of Optimization and Improvement of Mechanical Properties of Low Carbon Steel by the Process of Carburization
}

\author{
Mohd. Akhtar Raja, Manas Raj Mishra
}

\begin{abstract}
The heat treatment and carburization has been acknowledged by some means of improving the various properties of metals and alloys. In the present investigation the mechanical and wear behaviours of mild steels carburized at different temperature range of 850,900 and $9500 \mathrm{C}$ have been studied and it is found that the simple heat treatment greatly improves the hardness, tensile strength and wears resistance of the mild steels. The aim has been to examine the effects of these different carburization temperatures and conditions on the mechanical and wear properties of the carburized mild steels. For above purpose firstly the mild steels are carburized under the different temperature range as stated above and then it is tempered at $2000 \mathrm{C}$ for half an hour after this the carburized and tempered mild steels are subjected for different kind of test such as abrasive wear test, hardness test, tensile test and the toughness test. The results of these experiment shows that the process of carburization greatly improves the mechanical and wear properties like hardness, tensile strength and wear resistance and these properties increases with increase in the carburization temperature but apart from this the toughness property decreases and it is further decreases with increase in carburization temperature. The experimental results also shows that the mild steels carburized under different temperature range as stated above, with in which the mild steels carburized at the temperature of $9500 \mathrm{C}$ gives the best results for the different kinds of mechanical and wear properties because at this temperature it gives highest tensile strength, hardness and wear resistance, so it must be preferred for the required applications.
\end{abstract}

Index Terms - Carburization, Hardness, Toughness, tensile

\section{INTRODUCTION}

The carburization provides a gradual change in carbon content and carbide volume from the surface to the bulk, resulting in a gradual alteration of mechanical and wear properties. The heat treatment and carburization increases the mechanical and wear resistance. Carburizing is the addition of carbon to the surface of low-carbon steels at temperaturesl. generally between 850 and $950^{\circ} \mathrm{C}\left(1560\right.$ and $\left.1740^{\circ} \mathrm{F}\right)$, a 2 . which austenite, with its high solubility for carbon, is the3. stable crystal structure. Hardening is accomplished when the 4 . high-carbon surface layer is quenched to form marten site so5. that a high-carbon martensitic case with good wear and fatigue resistance is superimposed on a tough, low-carbon steel core. Carburizing steels for case hardening usually have base-carbon contents of about $0.2 \%$, with the carbon content of the carburized layer generally being controlled at between

Mohd Akhtar Raja, Mechanical Engineering, M.Tech Student, Department of Mechanical Engineering, Faculty of Engineering \& Technology, Rama University, Kanpur, India.

Mr. Manas Raj Mishra, Assistant Professor, Department of Mechanical Engineering, Faculty of Engineering \& Technology, Rama University
0.8 and $1 \% \mathrm{C}$. However, surface carbon is often limited to $0.9 \%$ because too high a carbon content can result in retained austenite and brittle marten site.

Carburizing is one of the most widely used surface hardening processes. The process involves diffusing carbon into a low carbon steel alloy to form a high carbon steel surface. Carburizing steel is widely used as a material of automobiles, form implements, machines, gears, springs and high strength wires etc. which are required to have the excellent strength, toughness, hardness and wear resistance, etc. Because these parts are generally subjected to high load and impact. Such mechanical properties and wear resistance can be obtained from the carburization and quenching processes. This manufacturing process can be characterized by the key points such as: it is applied to low carbon work pieces, work pieces are in contact with high carbon gas, liquid or solid, it produces hard work piece surface, work piece cores retain soft.

\section{CARBURATION PROCESS}

Carburization is simply defined as the addition of carbon to the surface of low carbon steel at temperature generally between 850-950 degree Celsius. Carburization is the most widely used method of surface hardening. It consist of enrichment of surface layers of low carbon / mild steel (c less than equal to $0.30 \%$ ) with carbon up to $0.8 \%$ to $1 \%$ by this way the good wear and fatigue resistance is superimposed on a tough low carbon steel core. usually have base-carbon contents of about $0.2 \%$, with the carbon content of the carburized layer generally being controlled at between 0.8 and $1 \% \mathbf{C}$. However, surface carbon is often limited to $0.9 \%$ because too high a carbon content can result in retained austenite and brittle marten site.

There are following types of carburization processes exist Solid carburization

Gaseous carburization

Vacuum carburization

Plasma carburization

Salt bath carburization

\section{MATERIAL AND METHODOLOGY}

This work was aims to determine to study the mechanical properties of low carbon steel by the process of carburization using the hardness test and toughness test.

Mechanical properties are strength, hardness, toughness, elasticity, plasticity, brittleness, and ductility and malleability are mechanical properties used as measurements of how metals behave under a load. These properties are described in 


\section{A Study of Optimization and Improvement of Mechanical Properties of Low Carbon Steel by the Process of Carburization}

terms of the types of force or stress that the metal must withstand and how these are resisted.

\section{A. Hardness test}

Rockwell hardness testing is a general method for measuring the bulk hardness of metallic and polymer materials. Although hardness testing does not give a direct measurement of any performance properties, hardness correlates with strength, wear resistance, and other properties. Hardness testing is widely used for material evaluation due to its simplicity and low cost relative to direct measurement of many properties.

This method consists of indenting the test material with a diamond cone or hardened steel ball indenter. The indenter is forced into the test material under a preliminary minor load FO usually $150 \mathrm{~kg}$. When equilibrium has been reached, an indicating device, which follows the movements of the indenter and so responds to changes in depth of penetration of the indenter, is set to a datum position. While the preliminary minor load is still applied an additional major load is applied with resulting increase in penetration. When equilibrium has again been reach, the additional major load is removed but the preliminary minor load is still maintained. Removal of the additional major load allows a partial recovery, so reducing the depth of penetration. The permanent increase in depth of penetration, resulting from the application and removal of the additional major load is used to calculate the Rockwell hardness number.

In present experimental work Rockwell hardness was measured on carburized and tempered mild steel samples which are carburized under different temperature range of 850,900 and 950 C. For each of the sample, test was conducted for

5 times and the average of all the samples was taken as the observed values in each case. The Fig. 1 shows the Rockwell hardness test.

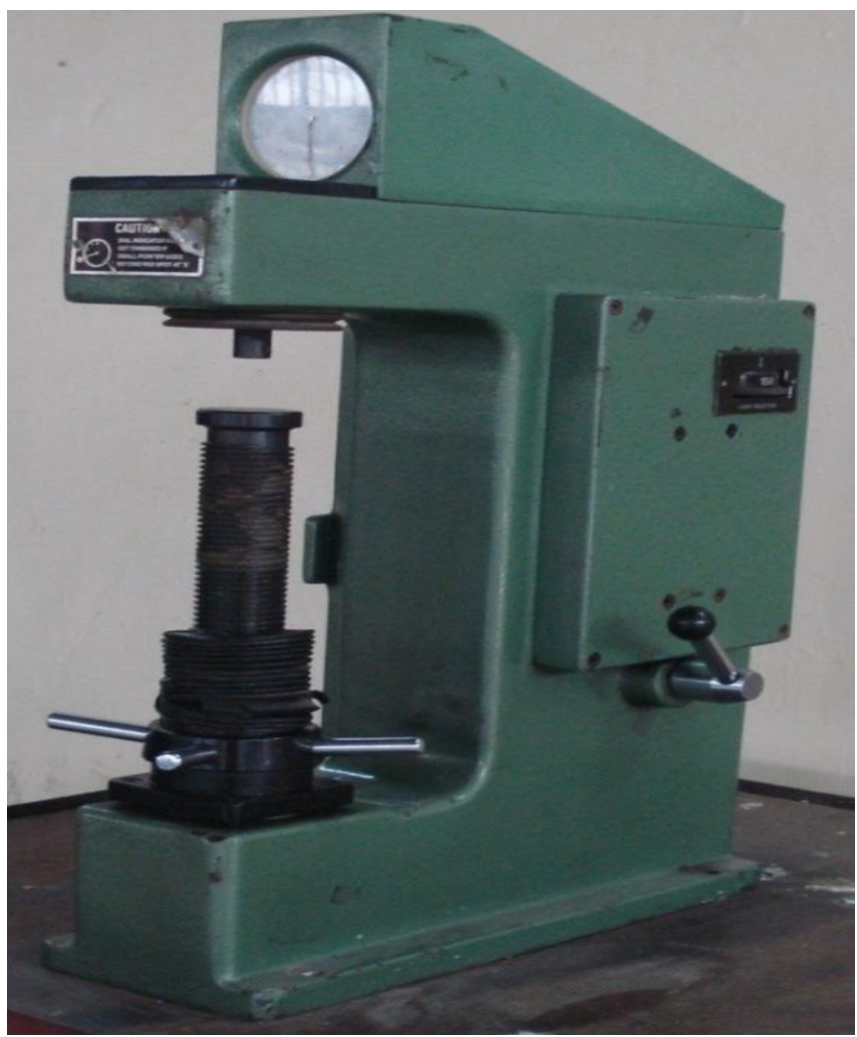

Fig. 1: Rock well hardness test

\section{B. Toughness (Charpy impact) test}

The test is conducted for the three different samples carbyrized under the three different temperatures of 850, 900 and $\mathrm{C}$. The test consist of measuring the energy absorbed in breaking a ASTM standard U-notched specimen by giving a single blow by swinging hammer. The specimen is simply supported at its ends. As the velocity of striking body is changed, there must occur a transfer of energy; work is done on the parts receiving the blow. The mechanics of impact involves not only the question of stresses induced, but also a consideration of energy transfer and of energy absorption and dissipation.

The ability of material to absorbed energy and deform plastically before fracture is called "toughness". It is usually measured by the energy absorbed in a notched impact test like charpy or izod tests. In present work for each of the sample, test was conducted for 3times and the average of all the samples was taken as the observed values in each case. As shown in Fig. 2.0 below.

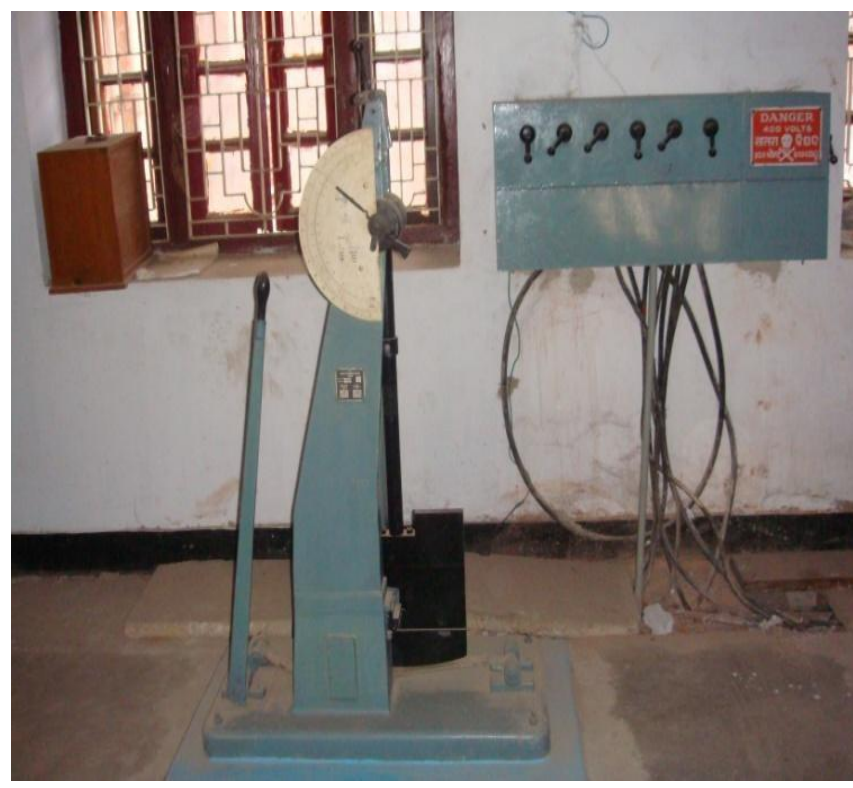

Fig. 2: Toughness (charpy impact) test

\section{RESULT AND DISCUSSION}

The result of hardness and toughness (charpy) can be summary in table one and two below in which their hardness numbers were found at different temperature that is 850,900 , and $950^{\circ} \mathrm{C}$.

Table 1: Hardness test Result

\begin{tabular}{|c|c|c|c|c|}
\hline TEMP & I & II & III & AVERAGE \\
\hline 850 & 39 & 45 & 39 & 41 \\
\hline 900 & 68 & 54 & 54 & 59 \\
\hline 950 & 50 & 61 & 52 & 54 \\
\hline
\end{tabular}

Table 2: Charpy impact test Result

\begin{tabular}{|c|c|c|c|c|}
\hline TEM & I & ii & iii & AVERAGE \\
\hline 850 & 240 & 270 & 260 & 257 \\
\hline 900 & 250 & 242 & 270 & 254 \\
\hline 950 & 278 & 238 & 115 & 233 \\
\hline
\end{tabular}




\section{CONCLUSION OF THE RESULT}

The mechanical and wear properties of mild steels were found to be strongly influenced by the process of carburization and carburizing temperature. The carburization process decreases the toughness of the mild steels. And the toughness is decreases with increase in the carburization temperature. Finally the net conclusion is that the mild steel carburized under the different temperature range of 850,900 , and $950^{\circ} \mathrm{C}$ with in which the mild steel carburized at the temperature of $950^{\circ} \mathrm{C}$ is giving the best results for the mechanical and wear properties like tensile strength, hardness and wear resistance.

\section{REFERENCES}

[1] AshishBhateja, A. V. (2012). Study the Effect on the Hardness of three Sample Grades of Tool Steel i.e. EN-31, EN-8, and D3 after heat treatment Processes Such As Annealing, Normalizing, and Hardening $\&$ Tempering. The International Journalof Engineering and Science (IJES), Vol.1 No.2, 253-259.

[2]Atik, E. Y. (March 2003, Vol.36). The effects of conventional heat treatment and boronizing on abrasive wear and corrosion of SAE 1010 , SAE 1040, D2 and 304 steels. Tribology International, 155-161.

[3]B. Selc, u. R. (2000). An investigation on surface properties of treated low carbon and alloyed steels (boriding and carburizing). Journal of Materials ProcessingTechnology, vol.103, 310-317.

[4]Demirkol, K. G. (1999). Effect of case depth on fatigue performance of AISI 8620 carburized steel. International Journal of Fatigue, Vol. 21, 207-212.

[5]EnverAtık, U. Y. (2003). The effects of conventional heat treatment and boronizing on abrasive wear and corrosion of SAE 1010, SAE 1040, D2 and 304 steels.

[6]Gadara, D. F. (2013). Corrosion Resistance of Heat-Treated NST 37-2 Steel in Hydrochloric Acid Solution. Journal of Minerals and Materials Characterizationand Engineering, Vol. 1, 1-7.

[7]FataiOlufemiAramide, S. A. (2009). Effects of Carburization Time and Temperature on the Mechanical Properties of Carburized Mild Steel, Using Activated Carbon as Carburizer.Materials Research, Vol. 12, No. 4, 483-487.

[8]Fitzgerald, C. (2006). Case hardening In a Home Garage.Hemmings Sports \& Exotic Car.

[9]Gopinath, A. (2013). Heat Treatment ofEN-8 Steel Casting Samples. India: metalworld.

[10] K. Palaniradja, N. A. (2010). Hardness and Case Depth Analysis Through Optimization Techniques in Surface Hardening Processes. The Open MaterialsScience Journal, Vol.4, 38-63.

[11] Akdemir A., Kus R. and Simsir M., Impact toughness and microstructure of continuous steel wire-reinforced cast iron composite, Material science and Engineering, (2009).

[12] Baldissera P. and Delprete C., Effect of deep cryogenic treatment on static mechanical properties of $18 \mathrm{NiCrMo} 5$ carburized steel, Material and design, 30 (2009): pp. 1435-1440

[13] Celik O., Ahlatci H. and Kayali E. S., High temperature tensile and abrasive wear characteristics of As-cast ductile iron, ISIJ International, 43 (2003): 1274-1279.

[14] Kumar M. and Gupta R. C., Abrasive wear characteristics of carbon and low alloy steels for better performance of farm implements, Journal of material science and technology, 11 (1995): pp. 91-96.

[15] Kumar M., Studies on the abrasive wear of carburized mild steels, Trans. Indian Inst. Metals, 47 (1994): pp. 417-420.

[16] Bepari M. M. A. and Haque M. N., Effects of Cr and Ni addition on the structure and properties of carburized low carbon steels, Trans. Indian Inst. Metals, 53 (2000) :pp. 509

[17] Wang Y. and Lei T., Study of Wear behavior of cast iron, Wear, 194 (1996): pp. 44.

[18] Kumar A., Corrosion inhibition of mild steels in hydrochloric acid by sodium lauryl sulphate, Journal of chemistry, 5 (2008): pp. 275-280.

[19] Kanisawa H. and Koyasu Y., development of high strength carburized steels for automobile gears, Nippon steel technical report, 65 (1995)

[20] Johnson A. and Randal J., The impact fatigue properties of iron and steels, Journal of sounds and vibration, 308 (2007): pp. 458-466 